\title{
Water flow and conductivity into capillary and non-capillary pores of soils
}

\author{
Abdelmonem M. Amer \\ Department of Soil Science, Faculty of Agriculture, Menoufia University, 32511 Shebin EI-Kom, Egypt. \\ E-mail address: amer_abdel@hotmail.com
}

\begin{abstract}
Downward water flow in the vadose zone occurs principally through the non-capillary pores, while the redistribution and lateral and upward flow occurs in the capillary pores. The purpose of this study was to propose equations to estimate water flow, $Q(\theta)$, and hydraulic conductivity, $K(\theta)$, in the capillary and non-capillary soil pores. The equations related $K(\theta)$ to soil pore radius $(r)$ were based on soil hydraulic data, including water retention $h(q)$, field basic infiltration rate, water sorptivity $(S)$ and distribution density function $f(r)$ of the soil pore size. Calcareous sandy loam and alluvial clay soils located at the Nile Delta were used to test the validity of the assumed equations. Data showed that the values of $K(\theta)$ calculated by the proposed equations were in the common ranges for such soils. The equations are therefore expected to be applicable for both coarse and fine textured soils. Also, an equation was derived to estimate the sorptivity at steady state infiltration. It was observed that $S$ is decreased in going from the un-saturation condition to steady state infiltration by $15.1 \%$ and $45.9 \%$ in sandy loam and clay soils, respectively.
\end{abstract}

Key words: Unsaturated hydraulic conductivity, soil pore size, water infiltration and sorptivity. 


\section{Introduction}

Mathematical models have become increasingly popular in the research and management of soil water flow and transport processes. The unsaturated hydraulic conductivity, $K(\theta)$, and the relationships between water content $(\theta)$, pressure head $(h)$ and soil pore size are important to quantify the rate of water flow and transport through the vadose zone. Water moves into soil pores due to gradients in water content and potentials, and this is usually from a wet soil to a dry one. The ability of pores to conduct water is controlled mainly by pore sizes, continuity and distribution of the pores in the soil. The soil pore sizes could be classified into macro (non-capillary) pores, coarse capillary pores and fine capillary pores (FCP) (Baver and Gardner 1972). The non-capillary pores are represented as rapidly draining pores $(R D P)$, while the coarse capillary pores $(C C P)$ are represented by the slowly draining pores $(S D P)$ and water holding pores (WHP) (Amer 2002). The pressure head corresponding with the cutoff between capillary and non-capillary pores varies widely, ranging from 0.1 $\mathrm{kPa}$ (Beven and Germann 1982) to $10 \mathrm{kPa}$ (Marshall 1956). In the present study, $h=10 \mathrm{kPa}$ has been selected as corresponding to the limit between capillary and non-capillary pores (Amer et al., 2009).

Theoretically, $K(\theta)$ may be predicted using statistical pore size distribution models, which assume water flow through " idealized " cylindrical pores. These models are described with the equations of Poiseuille and Darcy (Mualem 1976; Amer et al., 2009) in which water filled pores can be treated as capillary bundle tubes. The non-capillary pores have been recognized as significant pathways for water and solute movement in the soil. In most cases, macro (non-capillary) pores comprise only a small portion of the total soil voids, but under some conditions vertical flows through the macro pores dominate during infiltration (Chen and Wagenet 1992).
The aim of this work was to propose equations for predicting water flow and unsaturated hydraulic conductivity, $K(\theta)$, in capillary and non-capillary pores of soils. The approach is based on data on certain hydraulic parameters such as soil water retention y(q), distribution density function $f(r)$ of pore sizes and sorptivity at steady infiltration rate. These parameters can be measured experimentally and the procedures are not as time-consuming as measuring $K(\theta)$ in situ. Moreover, results of measuring $K(\theta)$ in situ are often unreliable.

\section{Theoretical background}

\subsection{Soil water retention and pore size classes}

Water is held in soil pores by cohesive and adhesive capillary forces. The size of the pores in unsaturated state can be determined through the so called hydraulic radius $(r)$ of a section of pore space. The relationship between $r$ and the capillary forces expressed as pressure head potential ( $h$ in $\mathrm{m}$ ) is represented by the capillary rise equation (Hillel 1980):

$$
h=\frac{2 \gamma \cos \alpha}{\rho_{w} g r}
$$

where, $r$ (in $\mathrm{m}$ ) is the equivalent cylindrical pore size (hydraulic) radius related to the meniscus curvature radius (R) via the equation; $r=R \cos \alpha$, and $\cos \alpha=1$, (as it was assumed that the contact angle $(\alpha)$ is 0 for a wetted surface), $\gamma$ is the surface tension between water and air (at $\left.20^{\circ} \mathrm{C}=0.0727 \mathrm{~kg} \mathrm{~s}^{-2}\right)$, $\mathrm{g}$ is the acceleration due to gravity $\left(9.8 \mathrm{~m} \mathrm{~s}^{-2}\right), \rho_{\mathrm{w}}$ is the density of water (at $20^{\circ} \mathrm{C}=998 \mathrm{~kg} \mathrm{~m}^{-3}$ ). As the soil dries out, increasing suction occurs due to the progressive emptying of capillary pores. Pore size diameters were determined for the ranges of soil matric potentials by applying Eq.(1) with respect to the soil water retention curves. 
The equivalent pressure $(\psi)$ ranges of $0-10,10-33$, $10-1500,33-1500$, and $>1500 \mathrm{kPa}$, are roughly corresponding to rapidly draining pores $(R D P)$, slowly draining pores $(S D P)$, coarse capillary pores $(C C P)$, water holding pores $(W H P)$, and fine capillary pores $(F C P)$ diameters. Classes can be combined into total draining pores $(T D P)(0-33 \mathrm{kPa})$, and total waterstorage pores $(W S P)(>33 \mathrm{kPa})$, as well as into macro (non-capillary) pores $(<10 \mathrm{kPa})$ and soil matrix (capillary) pores $(>10 \mathrm{kPa})$.

\subsection{Water flow in relation to soil capillary pores}

The defined ranges of soil pore sizes indicate that the rapidly drainable pores $(R D P)$ radius $(r)$ may range from $15-2500 \mu \mathrm{m}$ (Chen and Wagenet 1992). Within this range, as the radius increases, the Reynolds number (Re, dimensionless) for a water-filled- cylindrical pore (tube) will increase in value, creating a possible change in flow conditions from laminar to non-laminar flow:

$$
\operatorname{Re}=\frac{\text { inertiaforce }}{\text { viscousforce }}, \text { or } \operatorname{Re}=\frac{u \rho_{w} r}{\eta}
$$

where $u$ is the average flow velocity in the pores tube $\left(\mathrm{LT}^{-1}\right), r$ is an equivalent radius, and $\eta$ is the dynamic viscosity of water $\left(10^{-3} \mathrm{~kg} \mathrm{~m}^{-1} \mathrm{~s}^{-1}\right.$ at $\left.20 \mathrm{C}\right)$ and $\rho_{w}$ is the density of water $\left(10^{3} \mathrm{~kg} \mathrm{~m}^{-3}\right)$.

By incorporation of the Poiseuille equation for average velocity $\left[u=\frac{r^{2} \Delta p}{8 \eta \Delta l}\right]$ into Eq. 2, we get;

$$
\operatorname{Re}=\frac{r^{2} \Delta p}{8 \eta \Delta l} \cdot \frac{\rho_{w} r}{\eta} \text { or } \operatorname{Re}=\frac{r^{3} \rho_{w}{ }^{2} \Delta p}{8 \eta^{2} \rho_{w} \Delta l}
$$

where $\frac{\Delta p}{\Delta l}$ is pressure gradient, in units of $\mathrm{M} \mathrm{L}^{-2} \mathrm{~T}^{-2}$.
Given $\operatorname{Re}=1$ (i.e., inertia force $=$ viscosity force), and as gravity acceleration, $g=\frac{\Delta p}{\rho_{w} \Delta l}$ then from Eq.2a, the criteria radius $\left(r_{c}\right)$ between laminar and non-laminar flow can be calculated as (Chen and Wagenet,1992):

$$
r^{3}{ }_{c}=\frac{8 \eta^{2}}{\rho_{w}{ }^{2} g}
$$

By applying the aforementioned values of the parameters in the right term of the Eq.3, then the critical radius of pore is equal to $r_{c}=95 \mu \mathrm{m}$. As the water-filled, non-capillary pores $(R D P)$ have diameters $\geq 28.8 \mu \mathrm{m}$ $(r \geq 14.4 \mu \mathrm{m})$, so it is expected that $r_{c}$ divides the $R D P$ into laminar $(\operatorname{Re}<1$ at $r=14.4$ - $95 \mu \mathrm{m})$ and non-laminar $(\operatorname{Re}>1$ at $r>95 \mu m)$ water flow. The Poiseuille equation for average velocity $(u)$ of water can also be applied for a pore radius $\leq r_{\mathrm{c}}$ in the form (Amer et al., 2009):

$$
u=\frac{\rho_{w} g r^{2}}{8 \eta} \cdot \frac{\Delta h}{\Delta l}
$$

where, $\frac{\Delta h}{\Delta l}$ is the gradient hydraulic head $\left(\mathrm{m} . \mathrm{m}^{-1}\right)$, and $h$ is the hydraulic head (m), and $l$ is the length of pores tube. Then the flow rate, $\mathrm{Q}\left(\mathrm{L}^{3} \cdot \mathrm{T}^{-1}\right)$ for a single cylindrical pores tube is:

$$
Q=\pi r^{2} \frac{\rho_{w} g r^{2}}{8 \eta} \cdot \frac{\Delta h}{\Delta l}
$$

where $\pi r^{2}$ is the cross-sectional area of the soil pores. Soil matrix is assumed to behave as a homogeneous soil with a majority of capillary pores $(S D P+W H P+F C P)$, described by classical water flow equations based on Darcy's law, in which:

$$
Q=\pi r^{2} K \frac{\Delta h}{\Delta l}
$$


From the Poiseuille equation (5) and Eq. (6), the hydraulic conductivity, $K\left(\mathrm{LT}^{-1}\right)$ for one cylindrical capillary pore will be as:

$$
K=\frac{\rho_{w} g r^{2}}{8 \eta}
$$

If the distribution density function of pore sizes, $f(r)$, is defined for pore sizes from $r_{\text {min }}$ to $r_{\text {max }}$ within a unit area of a capillary bundle, the total water flow capacity $\mathrm{Q}\left(\mathrm{L}^{3} \mathrm{~T}^{-1}\right)$ at $\frac{\Delta h}{\Delta l}=1$, will be:

$$
Q(r)=\int_{r \min }^{r_{\max }} \pi r^{2} \frac{\rho_{w} g r^{2}}{8 \eta} f(r) d r
$$

For capillary pores, water flow $Q(r)$ can be formulated as follows:

$$
\begin{aligned}
& Q(r)=\int_{r W a}^{r F C P} \pi r_{F C P}^{2} \frac{\rho_{w} g r^{2}}{8 \eta} f(r) d r+\int_{r F C P}^{r W H P} \pi r_{W H P}^{2} \\
& \frac{\rho_{w} g r^{2}}{8 \eta} f(r) d r+\int_{r W H P}^{S D P} \pi r_{S D P}^{2} \frac{\rho_{w} g r^{2}}{8 \eta} f(r) d r
\end{aligned}
$$

where $r$ is the pore radius as applicable to the water adsorption capacity $(\mathrm{Wa})$ at which water does not move, fine capillary pores $(F C P)$, water holding pores $(W H P)$, and slowly drainable pores $(S D P)$, respectively. The pore radius was taken to be as the largest one for each class.

\subsection{Infiltration and hydraulic conductivity into non-capillary pores}

Under the conditions of non-laminar flow where $\operatorname{Re}>1$, the average flow velocity $(u)$ and then the hydraulic conductivity, $K$,can be estimated from the infiltration rate, $i$ and sorptivity, S. The infiltration rate (i) is the volume of water infiltrating through a horizontal unit area of soil surface at any instant (infinitely small period of time) and has unit of $\mathrm{LT}^{-1}$. The cumulative infiltration $(I)$ is the total volume of water that has infiltrated through a unit of horizontal area of soil surface over a given period of time, measured from the beginning of infiltration.. For many soils, a plot of $I$ as a function of time $t$ is described (in depth unit, $\mathrm{cm})$ by the equation of Kostiakov (1932):

$$
I=c t^{m}
$$

where, $c$ and $m$ are constants for a given soil and a given moisture content, respectively. These constants could be obtained if $\log I$ is plotted against $\log t$;

$$
\log I=\log c+m \log t
$$

At unit time, $I=c$, where $\log c=$ intercept and $m=$ slope of the linear regression of Eq.11.

The instantaneous infiltration rate $(i)$ at any time can be derived by differentiating the expression for $I$ (Eq.10) with respect to time $t$;

$$
i=\frac{d I}{d t}=c m t^{m-1}
$$

Philip (1957) showed that the cumulative infiltration, $I, \mathrm{~cm}$ in soil changes with square root of time $\left(t^{0.5}\right)$, with the $t$ in minutes, and it depending on the sorptivity $(S)$ of the soil. Sorptivity is the capacity of a soil to absorb (suck up) water and is influenced by the antecedent water content of the soil. If $I$ is plotted against $t^{0.5}$ then a linear relationship is usually found for the first 1 to 3 minutes of infiltration. The slope of the linear relationship, $S=\left[\frac{d I}{d \sqrt{t}}\right]$ allows to determine $S$ at the unit time. With respect to the Philip infiltration equation, the cumulative infiltration, $I$, and the sorptivity, $S$, can be calculated at relatively short periods of time as follows: 


$$
I \approx S t^{1 / 2}+a K_{s} t
$$

where $a$ is a constant ranged as $0 \leq a \leq 1$, and $K_{s}$ is the saturated hydraulic conductivity.

Philip (1969) and Swartzendruber and Young (1974) suggested that a fit of Eq.13 to the whole time of infiltration would lead to select $a \approx 1$. So, the Eq.13 can be rewritten as follows:

$$
S=\frac{I-K_{s} t}{t^{0.5}}
$$

After long periods of times, $t$ at which the instantaneous infiltration rate $(i)$ reached the basic infiltration rate $\left(i_{\mathrm{b}}\right)$, the steady state of water flow is predominant, and $i_{b}$ is supposed to be proportional to saturated hydraulic conductivity ( i.e. $i_{b}=a K s$ ). Amer (2011) proved that the matching factor $a$ (dimensionless) as a function between $i_{b}$ and $K s$, is:

$$
a=\frac{m \cdot i_{b} \cdot \sqrt{t}}{i_{b} \cdot \sqrt{t}-m S}
$$

where, the parameters in the right term of Eq.15 are the same as mentioned above.

In this study, $\mathrm{S}$, after a long period of time, $t \mathrm{hr}$ from the beginning infiltration, is denoted as wet sorptivity or steady state sorptivity, $\mathrm{S}_{\mathrm{w}}\left(\mathrm{LT}^{-0.5}\right)$. To estimate $\mathrm{S}_{\mathrm{w}}$, the Eq.14 should be developed using Eq.12 as follows:

$$
i=\frac{c \cdot t^{m} \cdot m}{t}
$$

At steady state infiltration, $i=i_{b}$, hence, substituting Eq.16 into Eq.10 produces:

$$
I=\frac{i_{b} \cdot t}{m}
$$

Incorporating Eq.17 into Eq.14, subsequently, we obtain:

$$
\begin{aligned}
& S_{w}=\frac{1}{\sqrt{t}}\left[\frac{i_{b} \cdot t}{m}-K_{s} t\right] \\
& \left.S_{w}=i_{b} \sqrt{t(} \frac{1-m}{m}\right) \\
& \text { and, } i_{b}=\frac{S_{w} m}{(1-m) \sqrt{t}}
\end{aligned}
$$

During infiltration, the application rate of water to soil surface is often greater than $\mathrm{K}(\theta)_{R D P}+\mathrm{K}(\theta)_{h}$, where $\mathrm{K}(\theta)_{R D P}$ is the hydraulic conductivity into the rapidly drainable pores and $\mathrm{K}(\theta)_{h}$ is the matrix unsaturated hydraulic conductivity. If the addition of water continues until the time of steady state infiltration is reached, it is expected that the macro non-capillary pores $(\Delta \theta)$ ${ }_{R D P}$ will eventually be completely saturated with water before the matrix is saturated (Chen and Wagenet 1992). Then the steady state infiltration rate can then be considered as $i_{b}=a K(\theta)_{\mathrm{RDP}}$ for rapidly drainable pores. In this case, the matching factor $(a)$ is assumed to represents the inverse of the saturation degree at steady state infiltration, i.e. $a=\frac{1}{\frac{(\Delta \theta)_{R D P}}{\theta_{s}}}$. Hence, combing these relationships with respect to Eq. 20, the $\mathrm{K}(\theta)_{R D P}$ can be estimated as follows :

$$
K(\theta)_{R D P}=\frac{S_{w} m}{(1-m) \sqrt{t}} \frac{(\Delta \theta)_{R D P}}{\theta_{s}}
$$

\subsection{Elapsed time for steady state infiltration}

The time, $t$, that must elapse before the instantaneously infiltration rate, $i$, becomes approximately constant can be expressed in term of the soil property, $m$. In this case, $i_{b}$ can be defined by differentiating $i$ with respect to time (Eq.12) and then by assuming that stability is reached when the change in $i$ values with time, t does not exceed $10 \%$ of $i$ at the previous hour, as follows (Amer, 2011): 


$$
\frac{d i}{d t}=-0.1 i
$$

where, from Eq.12; $-0.1 i=-0.1 c m t^{m-1} \quad$ then;

$$
\frac{d\left(c m t^{m-1}\right)}{d t}=(m-1) c m t^{m-2}=-0.1 c m t^{m-1}
$$

By solving for $\mathrm{t}$ in the right-hand two terms of the last equation, we find:

$$
t=10(1-m) \mathrm{hr} \text {, }
$$

2.5. $Q(\theta)$ and $K(\theta)$ in relation to soil water filled pores

For rapidly drainable pores (RDP), the existence of a range of pore sizes between $r_{\text {min }}$ and $r_{\max }$ (in Eq.8), allows definition of $Q(r)$ for capillary and non-capillary pores i.e. from $r_{\min }=14.4 \mu \mathrm{m}\left(=r_{S D P}\right)$ up to the critical radius $r_{c}(=95 \mu \mathrm{m})$ and from $r_{c}$ up to $r_{\text {max }}(\approx 1500 \mu \mathrm{m})$. The $r_{\max }$ represents the total pores of soil at saturation $(\mathrm{pF}=0)$. Substituting Eq.21 into Eq.8, the water flow into RDP can be obtained as follows:

$$
Q(r)=\int_{r_{S D P}}^{r c} \pi r_{c}^{2} \frac{\rho_{w} g r^{2}}{8 \eta} f(r) d r+\int_{r c}^{r \max } \pi r_{t}^{2} \frac{S}{t^{0.5} \frac{(1-m)}{m}} f(r) d r
$$

In practices, since the distribution density function, $f$ $(r)$, of pore sizes is difficult to obtain (Chen and Wagenet 1992), a conceptual method of water filled pores, $\Delta \theta$, is employed to estimate $f(r)$ function whereas the $f(r)$ is usually taken to be similar as the soil water retention $(\psi)$ function with $r$ corresponding to: $f(r)=\frac{d \theta}{d r}$ or $d \theta=f(r) d r$ where $\theta$ is the volumetric soil water content $\left(\mathrm{L}^{3} \mathrm{~L}^{-3}\right)$ corresponds to $\psi$ and $r$. Then;

$$
\Delta \theta=\int_{r \min }^{r \max } f(r) d r
$$

By substitution of Eq.25 in Eqns. 9 and 24, the total water flow, $Q(\theta)\left[\mathrm{L}^{3} \mathrm{~T}^{-1}\right]$, and hydraulic conductivity, $K(\theta)\left[\mathrm{LT}^{-1}\right]$, can be obtained for capillary and noncapillary pores as follows:

$$
\begin{aligned}
& Q(\theta)=\frac{\pi r^{2} S|\Delta \theta|_{r c}^{r \max }}{t^{0.5} \frac{(1-m)}{m}}+\frac{\pi \rho_{w} g r_{c}^{4}|\Delta \theta|_{r S D P}^{r c}}{8 \eta}+\frac{\pi \rho_{w} g r_{i}^{4}}{8 \eta} \sum_{i=W_{a}}^{i=S D P}(\Delta \theta)_{i} \\
& \text { As } K(\theta)=Q(\theta) / \pi r^{2}, \text { then: } \\
& K(\theta)=\frac{S|\Delta \theta|_{r c}^{r \max }}{t^{0.5} \frac{(1-m)}{m}}+\frac{\rho_{w} g r_{c}^{2}|\Delta \theta|_{r S D P}^{r c}}{8 \eta}+\frac{\rho_{w} g r_{i}^{2}}{8 \eta} \sum_{i=W_{a}}^{i=S D P}(\Delta \theta)_{i}
\end{aligned}
$$

Multiplying the first part of Eq.27 by a matching factor $K s / K c$, i.e. the ratio of the measured saturated $K_{s}$ to the calculated $K_{c}$ for total pores, the $K(\theta)$ can be rearranged as:

$K(\theta)=\left[\frac{K S}{K c}\right] \frac{m S|\Delta \theta|_{r c}^{r R D P}}{t^{0.5}(1-m)}+\frac{\rho_{w} g}{8 \eta}\left[r^{2}|\Delta \theta|_{r S D P}^{r c}+\sum_{i=W_{a}}^{i=S D P}(\Delta \theta)_{i} r_{i}^{2}\right]$ where $\Delta \theta$ is the change in the ratio of volume fraction $\left(\mathrm{L}^{3} \cdot \mathrm{L}^{-3}\right)$ of moisture, going from soil pores occupied by water from the pores of immobile water (soil moisture adsorption capacity, $W a$ ) up to slowly drainable pores $(S D P)$. The $\Delta \theta$ can be expressed as a fraction of the soil bulk volume (as in Eq.28), or as ratio of total pores $(\Delta \theta / \theta \mathrm{s})$. When this fraction is substituted for $\Delta \theta$ 
in Eqns 28 and 26, the results are:

$$
\begin{aligned}
& K(\theta)=\left[\frac{K s}{K c}\right] \frac{m S|\Delta \theta|_{r c}^{r R D P}}{t^{0.5}(1-m) \theta_{s}}+\frac{\rho_{w} g}{8 \eta}\left[r_{c}^{2} \frac{|\Delta \theta|_{r S D P}^{r c}}{\theta_{s}}+\sum_{i=W a}^{i-S D P} \frac{(\Delta \theta)_{i}}{\theta_{s}} r_{i}^{2}\right] \\
& Q(\theta)=\frac{\pi r^{2} S|\Delta \theta|_{r c}^{r \max }}{t^{0.5} \frac{\pi(-m)}{m} \theta_{s}}+\frac{\pi \rho_{w} g r_{c}^{4}|\Delta \theta|_{r s D P}^{r c}}{8 \eta \theta_{s}}+\frac{\pi \rho_{w} g r_{i}^{4}}{8 \eta} \sum_{i=w_{a}}^{i=S D P} \frac{(\Delta \theta)_{i}}{\theta_{s}}
\end{aligned}
$$

The critical pore radius $\left(r_{c}\right)$ between laminar and turbulent flow is corresponding to the critical moisture content, and $r_{c}$ which can be estimated indirectly from soil moisture retention curve at $r_{c}=95 \mu \mathrm{m}$. Regardless of the value of $r_{c}$, the rapid water flow in the non-capillary pores will result in some transfer of water into the soil matrix through the macro-pore wall due to the difference in water potential between the macro-pore and the matrix. The $K$ cutoff point is for the largest $r$ of each certain class, and this was matched with the corresponding $\Delta \theta$ class, and the $W a$ was subtracted from $\Delta \theta$ of the $>1500 \mathrm{kPa}$ class. Larger classes are accumulated of the $K$ 's from smaller classes. The value of hydraulic conductivity $K(\theta)$ is recognized as being it depends on the nature of the medium and the physical properties; $\left(\rho_{w} g / \eta\right)$ of the perfuse water.

\section{Material and methods}

Two soil profiles were chosen to investigate the applicability of the suggested equations. The first soil profile (I) is a calcareous sandy loam soil located at the Nubaria area (northern west Nile Delta). The second (II) is an alluvial clay soil from the farm of the Faculty of Agriculture, Menoufia University, at Shebin Elkom (middle Nile Delta). Disturbed and undisturbed soil samples were taken from each of three depths for each soil profile. The undisturbed soil samples were used to determine bulk density, and saturated hydraulic conductivity by using the constant head method (Klute and Dirksen, 1986). The de-sorption soil water retention curve, for pressure heads $h$ up to about $100 \mathrm{kPa}$, was determined using undisturbed samples for clay soil (profile II), and a neutron probe and tensiometers were used in situ for calcareous soil (profile I). The determination of soil moisture content $(\theta)$, on volume basis, was extended in the laboratory at different $h$ values up to $1500 \mathrm{kPa}$ for the two soil profiles. The data of pore size were obtained using the soil water retention $h(\theta)$ curves, and then classified diametrically upon Eq.1. The pore size distribution was expressed as a percent of soil bulk volume $(\Delta \theta \%)$ and of total pores volume, $\left(\Delta \theta / \theta_{\mathrm{s}}\right) \times 100$, (where $\theta_{\mathrm{s}}$ is saturation degree). Disturbed samples were air-dried, gently crushed, sieved through a $2 \mathrm{~mm}$ sieve, and used for analysis of de-sorption at higher pressure heads, $\mathrm{CaCO}_{3}$ content, texture, saturated hydraulic conductivity $\left(K_{s}\right)$, salinity (EC), and sodium adsorption ratio (SAR) These analyses were done following the procedures as mentioned by Sparks et al. (1996) and Dane and Topp (2002). As given in Amer (1993, 2009), we used the water vapour adsorption isotherm method, with applying the BET theory to estimate the moisture adsorption capacity $(\mathrm{Wa}$ ), which is considered to be immobile water content in a soil. $W a$ is equal to three layers of adsorbed water (films); $W a=W m+2 W m e$ where, $W m$ is the mono-adsorbed layer of water vapor on soil particles, and Wme is the external mono-adsorbed layer of water vapor. Some physical and chemical properties of the studied soils are shown in Table 1. 
Table 1. Some physical and chemical properties of the studied soils.

\begin{tabular}{|c|c|c|c|c|c|c|c|c|c|c|c|}
\hline \multirow{2}{*}{$\begin{array}{l}\text { Soil pro- } \\
\text { file and } \\
\text { location }\end{array}$} & \multirow{2}{*}{$\begin{array}{l}\text { Soil } \\
\text { depth } \\
(\mathrm{cm})\end{array}$} & \multirow{2}{*}{$\begin{array}{c}\mathrm{EC}^{\dagger} \\
\mathrm{dS} \mathrm{m}^{-1}\end{array}$} & \multirow{2}{*}{ SAR } & \multirow{2}{*}{$\begin{array}{c}\rho b \\
\text { g. } \mathrm{cm}^{-3}\end{array}$} & \multirow{2}{*}{$\begin{array}{c}\mathrm{CaCO}_{3} \\
\%\end{array}$} & \multicolumn{3}{|c|}{$\begin{array}{c}\text { Particle size } \\
\text { distribution \% }\end{array}$} & \multirow{2}{*}{$\begin{array}{l}\text { Texture } \\
\text { class }\end{array}$} & \multirow{2}{*}{$\begin{array}{c}\text { Wa } \\
\mathrm{m}^{3} \mathrm{~m}^{-3}\end{array}$} & \multirow{2}{*}{$\begin{array}{c}\mathrm{Ks} \\
\mathrm{cm} \mathrm{h}^{-1}\end{array}$} \\
\hline & & & & & & Sand & Silt & Clay & & & \\
\hline \multirow{3}{*}{$\begin{array}{l}\text { I } \\
\text { Nubaria }\end{array}$} & $0-20$ & 0.34 & 0.68 & 1.47 & 22 & 64.0 & 19.9 & 16.1 & $\begin{array}{l}\text { Sandy } \\
\text { loam }\end{array}$ & 0.0315 & 4.40 \\
\hline & $20-40$ & 0.26 & 0.40 & 1.46 & 23 & 61.8 & 20.3 & 17.9 & $\begin{array}{l}\text { Sandy } \\
\text { loam }\end{array}$ & 0.0298 & 4.58 \\
\hline & $40-60$ & 0.24 & 0.33 & 1.46 & 26 & 60.9 & 22.1 & 17.0 & $\begin{array}{l}\text { Sandy } \\
\text { loam }\end{array}$ & 0.0260 & 4.66 \\
\hline \multirow{3}{*}{$\begin{array}{l}\text { II } \\
\text { Shebin } \\
\text { El-Kom }\end{array}$} & $0-30$ & 1.90 & 3.79 & 1.30 & 2.10 & 23.8 & 35.2 & 41.0 & Clay & 0.1100 & 1.60 \\
\hline & $30-60$ & 1.60 & 4.73 & 1.38 & 1.84 & 23.6 & 34.7 & 41.7 & Clay & 0.1183 & 1.22 \\
\hline & $60-90$ & 2.00 & 9.90 & 1.35 & 0.92 & 22.3 & 32.9 & 44.8 & Clay & 0.1227 & 0.58 \\
\hline
\end{tabular}

${ }^{\dagger} E C$ is electrical conductivity, $S A R$ is sodium adsorption ratio, $\rho_{\mathrm{b}}$ is bulk density, $W a$ is adsorption moisture ratio, and $K S$ is saturated hydraulic conductivity.

The unsaturated hydraulic conductivity, $K(\theta)$, values were calculated by Eq.29 and compared with estimated data $\left(K_{G}\right)$ by van-Genuchten's equation (1980) in calcareous soil:

$$
K_{G}=K S S e^{0.5}\left[1-\left(1-S e^{1 / n}\right)^{n}\right]^{2}
$$

where, $S_{e}=\left[\frac{\theta-\theta_{r}}{\phi-\theta_{r}}\right]$ is the volumetric soil moisture content at the moisture suction $h, \mathrm{kPa}, \theta_{r}$ is the residual moisture content, (in this study $\theta r=\rho_{b} W a$ ), $\phi$ is total porosity, and $n$ is a constant depending on the fitting of the sigmoid curve.

Field infiltration rate was obtained with the double ring infiltrometer (Reynolds et al., 2002). The sorptivity and infiltration parameters were done for both locations of soil profiles. Measured intake rates for individual infiltration runs were obtained at 2 to 10-minute intervals for the triplicates measurements of the locations. Infiltration rates ( $i$ in $\mathrm{cm} / \mathrm{h}$ ), as fitted to the Kostiakov equation (1932) were measured in the experimental field.

\section{Results and discussion}

\subsection{Capillary and non-capillary pores}

Table 2 shows the pore size distribution; RDP, SDP, WHP, and FCP as derived from the soil moisture retention data of the studied soils applying the Eq.1. The non-capillary rapidly drainable pores (RDP) and ratio of air to water $(\mathrm{A} / \mathrm{W})$ indicated that the total drained pores, as compared with the capillary and water storage pores, were higher in the sandy loam soil (profile I) than in the clay soil (Profile II). This is due to the relatively coarse texture and high $\mathrm{CaCO}_{3}$ content in the profile I. The maximum value of $\mathrm{A} / \mathrm{W}$ ratio was observed in the surface depth of the sandy loam soil, but it was occurred in the subsurface depth of the clay soil. As expected, the numbers of capillary pores were as much as high in the clay soil (fine textured profile) if compared to the sandy loam soil profile. 
Table 2. Pore size classes as a percent of soil bulk volume $(\Delta \mathrm{q} \%)$ and ratio of total volume pores $\left(\frac{\Delta \theta}{\theta_{S}}\right)$.

\begin{tabular}{|c|c|c|c|c|c|c|c|c|c|c|c|c|c|c|}
\hline $\begin{array}{l}\text { Soil } \\
\text { profile and } \\
\text { location }\end{array}$ & $\begin{array}{l}\text { Soil } \\
\text { depth } \\
(\mathrm{cm})\end{array}$ & $\begin{array}{r}\mathrm{RD} \\
\Delta \theta \%\end{array}$ & $\frac{\Delta \theta}{\theta_{S}}$ & $\begin{array}{r}\text { SD } \\
\Delta \theta^{\circ} \%\end{array}$ & $\frac{\Delta \theta}{\theta_{S}}$ & $\begin{array}{r}\text { TL } \\
\Delta \theta \%\end{array}$ & $\frac{\Delta \theta}{\theta_{S}}$ & $\begin{array}{r}\mathrm{WH} \\
\Delta \theta \%\end{array}$ & $\frac{\Delta \theta}{\theta_{S}}$ & $\begin{array}{r}\mathrm{CC} \\
\Delta \theta \%\end{array}$ & $\frac{\Delta \theta}{\theta_{S}}$ & $\begin{array}{r}\mathrm{FC} \\
\Delta \theta \%\end{array}$ & $\frac{\Delta \theta}{\theta_{S}}$ & $\begin{array}{c}\text { TVP A/W } \\
\%\end{array}$ \\
\hline \multirow{3}{*}{ I Nubaria } & $0-20$ & 14.6 & 0.369 & 11.10 & 0.280 & 25.72 & 0.649 & 6.40 & 0.162 & 17.50 & 0.442 & 7.50 & 0.189 & $39.62 \quad 1.85$ \\
\hline & $20-40$ & 13.8 & 0.385 & 10.01 & 0.278 & 23.86 & 0.663 & 4.93 & 0.137 & 14.94 & 0.415 & 7.18 & 0.199 & $35.97 \quad 1.97$ \\
\hline & $40-60$ & 12.8 & 0.364 & 9.42 & 0.267 & 22.24 & 0.631 & 6.00 & 0.170 & 15.42 & 0.437 & 7.00 & 0.198 & $35.24 \quad 1.71$ \\
\hline \multirow{3}{*}{$\begin{array}{l}\text { II } \\
\text { Shebin } \\
\text { El-Kom }\end{array}$} & $0-30$ & 1.25 & 0.190 & 8.10 & 0.123 & 9.35 & 0.142 & 31.68 & 0.482 & 39.78 & 0.605 & 24.74 & 0.376 & $\begin{array}{ll}65.77 & 0.17\end{array}$ \\
\hline & $30-60$ & 1.33 & 0.192 & 16.30 & 0.235 & 17.63 & 0.254 & 28.90 & 0.417 & 45.20 & 0.652 & 22.78 & 0.328 & $69.31 \quad 0.34$ \\
\hline & $60-90$ & 2.00 & 0.302 & 13.28 & 0.200 & 15.28 & 0.231 & 29.54 & 0.446 & 42.82 & 0.646 & 21.46 & 0.324 & $66.28 \quad 0.30$ \\
\hline
\end{tabular}

$\mathrm{A} / \mathrm{W}$ is Air/Water ratio or $\mathrm{A} / \mathrm{W}=\mathrm{TDP} /(\mathrm{WHP}+\mathrm{FCP})$

\subsection{Infiltration and sorptivity}

Experimentally, the typical trends in cumulative infiltration, $I(\mathrm{~cm})$ versus time $t$ (minute) and infiltration rate, $i(\mathrm{~cm} / \mathrm{h})$ are illustrated by the empirical power functions, $I=1.44 \mathrm{t}^{0.65}, i=56 \mathrm{t}^{-0.35}$, and $I=0.6 \mathrm{t}$ ${ }^{0.53}, i=19.1 \mathrm{t}^{-0.47}$ in sandy loam (profile $\mathrm{I}$ ) and clay (profile II) soils, respectively. At the onset of wetting, the moisture gradient was the greatest, hence the more rapid infiltration. The infiltration rate $i\left(\mathrm{LT}^{-1}\right)$ slowed down gradually with time $t$ and reached the steady state (basic infiltration rate, $i_{b}$ ) after 3.5 and 4.7 hours (Eq.23) from the beginning of infiltration for I and II soil profiles, respectively. At the beginning of infiltration (un-saturation conditions), the sorptivity, S, was calculated using $I$ as a function of time $t^{m}$ where $m$ was adjusted to 0.5 . The $\mathrm{S}$ values were found as $1.324 \mathrm{~cm} /$ $\min ^{0.5}$ and $0.618 \mathrm{~cm} / \mathrm{min}^{0.5}$ for the profiles I and II, respectively. After a long time of infiltration, the sorptivity may be called steady state sorptivity or wet sorptivity $\left(\mathrm{S}_{\mathrm{w}}\right)$ (Amer 2011). Using Eq.19 to calculate $\mathrm{S}_{\mathrm{w}}$, it was observed that at steady state infiltration the sorptivity values were 1.124 and $0.334 \mathrm{~cm} / \mathrm{min}^{0.5}$, i.e., decreased by $15.1 \%$ and by $45.95 \%$ for I and II soil profiles, respectively. It means that a dry soil (unsaturated) typically has a much greater sorptivity than a wet soil. Though a soil with larger (non-capillary) pores has a lower sorptivity than a soil with smaller (capillary) pores (Hallett 2008), $S$ was higher in sandy loam (calcareous) soil than in clay soil. This result attributed to the abundance of the $\mathrm{CaCO}_{3}$ fraction which has a great ability to suck up water in such calcareous soil (Ghazy, 1993).

\subsection{Water flow rate}

The flow of water under saturated conditions is a function of two opposing factors, namely, the effective pore size and the continuity of water films in the conducting pores. At a given suction, the decrease in pore size facilitates the flow of water by increasing the continuity of the water films in the water conducting pores (Amer 2003). Simultaneously, however, it slows down the flow of water by the increased resistance in pores because from Poiseuille's law and the present derived equations, the water flow rate per unit cross-section area of pores is proportional to the square of the pore radius $\left(r^{2}\right)$. The ultimate effect of 
particle-size/pore size (capillary and non-capillary) distribution on unsaturated water flow is thus the resultant of these two opposing phenomena (Mundra et al., 1989). However, as the values of $K(\theta)$ increased with an increase in water content $(\theta)$, the water flow rate $Q(\theta)$ must obey the same trend of $K(\theta)$ for the same radius, since; $Q(\theta)=\pi r^{2} K(\theta)$.

\subsection{Unsaturated hydraulic conductivity}

Data presented in Table 3 show the values of unsaturated hydraulic conductivity, $K(\theta)$, as calculated by Eq.29 at different soil pore size classes. It was evident that the values of hydraulic conductivity for fine capillary pores, $\left(K(\theta)_{F C P}\right)$, were very low in the soil matrix whereas they fluctuated between (3.26-4.17) $\mathrm{x} 10^{-9}$ and $(0.38-2.30) \times 10^{-8} \mathrm{~cm} / \mathrm{s}$ in the I and II soil profiles, respectively. As expected the values of $K(\theta)$ increased with increase in capillary and non-capillary pore sizes from $F C P$ to $S D P$ and up to $R D P$ (Fig.1). The larger the pore size the greater is the hydraulic conductivity (Ahuja et al., 1989). The values of $K(\Delta \theta)_{\mathrm{RDP}}$ in the range of non-capillary pores remained smaller than those for the range of soil matrix (capillary) pores $\left(K(\Delta \theta)_{h}\right)$, in clay soil (Profile II). On the contrary, the $K(\Delta \theta)_{R D P}$ and $K(\Delta \theta)_{S D P}$ values were higher in sandy loam soil (profile I) than that in soil matrix pores. This is due to the relatively large pores and high $R D P$ fraction percent of all depths of the sandy calcareous soil (profile I) as compared to the clay soil (Table 2). The opposite was observed for $W H P$ and $F C P$ where $K(\Delta \theta)_{h}$ values were higher for all depths of the clay soil than in the sandy loam soil.

In comparison with the van-Genuchten's model, the predicted values of $K(\theta)$ by the suggested equation (29) were in consistent with those calculated by van-Genuchten's model (Eq.31) $\left(K(\theta)_{G}\right)$ for the water holding pores values, $W H P$. The calculated $K(\theta)_{G}$ values were obtained only for sandy calcareous soil (profile I), whereas the values of the constant $n$ (in Eq.31) were $0.1837,0.1632$, and 0.1603 for the calcareous soil depths; 0-20, 20-40, and 40-60 cm respectively.

However, the values of $K(\theta)_{G}$ were relatively inconsistent for the other pore size classes. These results may be due to the fact that the calculation of the $n$ constant was done only over the water retention range 0-100 $\mathrm{kPa}$ of the soil moisture characteristic curve. This range includes the values of air-entry point and $(\Delta \theta)_{\mathrm{WHP}}$. In general, the values of the predicted $K(\theta)$ were less by about 3 times than those of $K(\theta)_{G} / K s$ for calcareous soil (Table 3). 
Table 3. Hydraulic conductivity $\mathrm{K}(\theta)$ in the capillary and non-capillary pores of the studied soils.

\begin{tabular}{|c|c|c|c|c|c|c|c|c|c|c|c|c|c|}
\hline \multirow{2}{*}{$\begin{array}{l}\text { Soil pro- } \\
\text { file and } \\
\text { location }\end{array}$} & \multirow{2}{*}{$\begin{array}{l}\text { Soil } \\
\text { depth } \\
(\mathrm{cm})\end{array}$} & \multicolumn{2}{|c|}{ FCP } & \multicolumn{2}{|c|}{ WHP } & \multicolumn{2}{|c|}{ SDP } & \multicolumn{2}{|c|}{ RDP } & \multicolumn{2}{|c|}{$\begin{array}{c}\Sigma \mathrm{K}(\Delta \theta) \\
\text { (calculated } \\
\text { by Eq.30) }\end{array}$} & \multicolumn{2}{|c|}{$\begin{array}{c}\mathrm{K}(\theta) \text {, by van } \\
\text { Genuchten's } \\
\text { Model }\end{array}$} \\
\hline & & $\begin{array}{l}\mathrm{K}(\Delta \theta) \\
\mathrm{cm} / \mathrm{s}\end{array}$ & $\begin{array}{l}\mathrm{K}(\Delta \theta) \mathrm{x} \\
\mathrm{Ks} / \mathrm{Kc} \\
\mathrm{cm} / \mathrm{s}\end{array}$ & $\begin{array}{l}\mathrm{K}(\Delta \theta) \\
\mathrm{cm} / \mathrm{s}\end{array}$ & $\begin{array}{l}\mathrm{K}(\Delta \theta) \mathrm{x} \\
\mathrm{Ks} / \mathrm{Kc} \\
\mathrm{cm} / \mathrm{s}\end{array}$ & $\begin{array}{c}\mathrm{K}(\Delta \theta) \\
\mathrm{cm} / \mathrm{s}\end{array}$ & $\begin{array}{l}\mathrm{K}(\Delta \theta) \mathrm{x} \\
\mathrm{Ks} / \mathrm{Kc} \\
\mathrm{cm} / \mathrm{s}\end{array}$ & $\begin{array}{l}\mathrm{K}(\Delta \theta) \\
\mathrm{cm} / \mathrm{s}\end{array}$ & $\begin{array}{c}\mathrm{K}(\Delta \theta) \mathrm{x} \\
\mathrm{Ks} / \mathrm{Kc} \\
\mathrm{cm} / \mathrm{s}\end{array}$ & $\begin{array}{l}\mathrm{K}(\theta)_{h} \\
\mathrm{~cm} / \mathrm{s}\end{array}$ & $\begin{array}{l}\mathrm{K}(\theta)^{*} \\
\mathrm{~cm} / \mathrm{s}\end{array}$ & $\begin{array}{l}\mathrm{K}_{\mathrm{G}} \\
\mathrm{cm} / \mathrm{s}\end{array}$ & $\mathrm{K}_{\mathrm{G}} / \mathrm{K}_{\mathrm{s}}$ \\
\hline \multirow{3}{*}{$\begin{array}{c}\text { I } \\
\text { Nubaria }\end{array}$} & $0-20$ & & $\begin{array}{l}3.260 \\
\times 10^{-9}\end{array}$ & $\begin{array}{l}5.973 \\
\times 10^{-6}\end{array}$ & $\begin{array}{l}1.448 \\
\times 10^{-5}\end{array}$ & $\begin{array}{l}9.681 \\
\times 10^{-5}\end{array}$ & $\begin{array}{l}2.347 \\
\times 10^{-4}\end{array}$ & $\begin{array}{l}4.011 \\
\times 10^{-4}\end{array}$ & $\begin{array}{l}9.726 \\
\times 10^{-4}\end{array}$ & $\begin{array}{l}2.493 \\
\mathrm{x} 10^{-4}\end{array}$ & $\begin{array}{l}1.222 \\
\times 10^{-3}\end{array}$ & $\begin{array}{l}5.81 \\
\times 10^{-6}\end{array}$ & $\begin{array}{l}4.75 \\
\times 10^{-3}\end{array}$ \\
\hline & $20-40$ & $\begin{array}{l}1.394 \\
\times 10^{-9}\end{array}$ & $\begin{array}{l}3.570 \\
\times 10^{-9}\end{array}$ & $\begin{array}{l}5.668 \\
\times 10^{-6}\end{array}$ & $\begin{array}{l}1.451 \\
\times 10^{-5}\end{array}$ & $\begin{array}{l}9.927 \\
\times 10^{-5}\end{array}$ & $\begin{array}{l}2.542 \\
\times 10^{-4}\end{array}$ & $\begin{array}{l}3.918 \\
\times 10^{-4}\end{array}$ & $\begin{array}{l}1.003 \\
\times 10^{-3}\end{array}$ & $\begin{array}{l}2.686 \\
\mathrm{x} 10^{-4}\end{array}$ & $\begin{array}{l}1.272 \\
\times 10^{-3}\end{array}$ & $\begin{array}{l}3.71 \\
\times 10^{-6}\end{array}$ & $\begin{array}{l}3.04 \\
\times 10^{-3}\end{array}$ \\
\hline & $40-60$ & $\begin{array}{l}1.409 \\
\times 10^{-9}\end{array}$ & $\begin{array}{l}4.170 \\
\times 10^{-9}\end{array}$ & $\begin{array}{l}6.545 \\
\times 10^{-6}\end{array}$ & $\begin{array}{l}1.925 \\
\times 10^{-5}\end{array}$ & $\begin{array}{l}9.801 \\
\times 10^{-5}\end{array}$ & $\begin{array}{l}2.901 \\
\times 10^{-4}\end{array}$ & $\begin{array}{l}3.327 \\
\times 10^{-4}\end{array}$ & $\begin{array}{l}9.847 \\
\times 10^{-3}\end{array}$ & $\begin{array}{l}3.096 \\
\times 10^{-4}\end{array}$ & $\begin{array}{l}1.294 \\
\times 10^{-3}\end{array}$ & $\begin{array}{l}5.82 \\
\times 10^{-6}\end{array}$ & $\begin{array}{l}4.76 \\
\times 10^{-3}\end{array}$ \\
\hline \multirow{3}{*}{$\begin{array}{l}\text { II } \\
\text { Shebin } \\
\text { El-Kom }\end{array}$} & $0-30$ & $\begin{array}{l}2.559 \\
\times 10^{-9}\end{array}$ & $\begin{array}{l}2.304 \\
\mathrm{x} 10^{-8}\end{array}$ & $\begin{array}{l}1.096 \\
\mathrm{x} 10^{-5}\end{array}$ & $\begin{array}{l}9.864 \\
\times 10^{-5}\end{array}$ & $\begin{array}{l}3.128 \\
\mathrm{x} 10^{-5}\end{array}$ & $\begin{array}{l}2.815 \\
\times 10^{-4}\end{array}$ & $\begin{array}{l}7.104 \\
\mathrm{x} 10^{-6}\end{array}$ & $\begin{array}{l}6.393 \\
\times 10^{-5}\end{array}$ & $\begin{array}{l}3.801 \\
\mathrm{x} 10^{-4}\end{array}$ & $\begin{array}{l}4.440 \\
\times 10^{-4}\end{array}$ & & - \\
\hline & $30-60$ & $\begin{array}{l}1.935 \\
\times 10^{-9}\end{array}$ & $\begin{array}{l}8.581 \\
\times 10^{-9}\end{array}$ & $\begin{array}{l}9.488 \\
\times 10^{-6}\end{array}$ & $\begin{array}{l}4.207 \\
\times 10^{-5}\end{array}$ & $\begin{array}{l}5.974 \\
\times 10^{-5}\end{array}$ & $\begin{array}{l}2.649 \\
\times 10^{-4}\end{array}$ & $\begin{array}{l}7.173 \\
\times 10^{-6}\end{array}$ & $\begin{array}{l}3.181 \\
\mathrm{x} 10^{-5}\end{array}$ & $\begin{array}{l}3.070 \\
\times 10^{-4}\end{array}$ & $\begin{array}{l}3.388 \\
\mathrm{x} 10^{-4}\end{array}$ & & - \\
\hline & $60-90$ & $\begin{array}{l}1.698 \\
\times 10^{-9}\end{array}$ & $\begin{array}{l}3.783 \\
\times 10^{-9}\end{array}$ & $\begin{array}{l}1.014 \\
\times 10^{-5}\end{array}$ & $\begin{array}{l}2.259 \\
\times 10^{-5}\end{array}$ & $\begin{array}{l}5.089 \\
\times 10^{-5}\end{array}$ & $\begin{array}{l}1.134 \\
\times 10^{-4}\end{array}$ & $\begin{array}{l}1.128 \\
\times 10^{-5}\end{array}$ & $\begin{array}{l}2.513 \\
\times 10^{-5}\end{array}$ & $\begin{array}{l}1.359 \\
\times 10^{-4}\end{array}$ & $\begin{array}{l}1.611 \\
\times 10^{-4}\end{array}$ & & - \\
\hline
\end{tabular}

${ }^{*} \mathrm{~K}(\theta)=\mathrm{K}(\theta)_{h}+\mathrm{K}(\Delta \theta)_{\mathrm{RDP}} \mathrm{x} \mathrm{Ks} / \mathrm{Kc}, \mathrm{K}(\theta)_{h}=\mathrm{Ks} / \mathrm{Kc}\left(\mathrm{K}(\Delta \theta)_{\mathrm{FCP}}+\mathrm{K}(\Delta \theta)_{\mathrm{WHP}}+\mathrm{K}(\Delta \theta)_{\mathrm{SDP}}\right)$

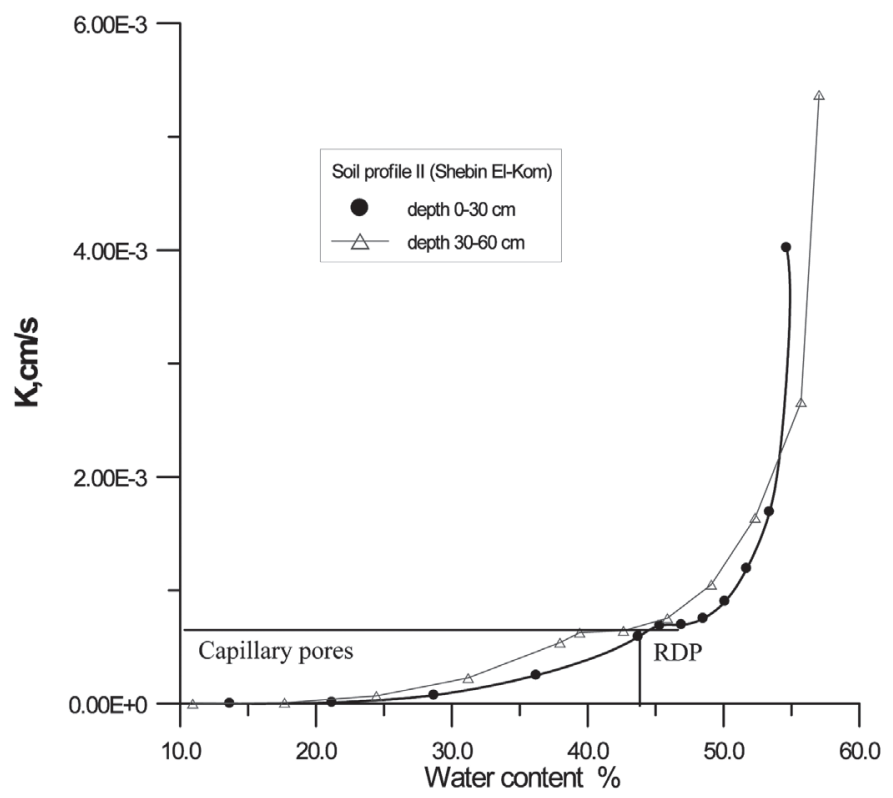

Figure 1. Unsaturated hydraulic conductivity in capillary and rapidly drainable pores of clay soil (profile II). 


\section{Conclusions}

The characterization of water flow properties and unsaturated hydraulic conductivity in the root zone of soils has become an ever-increasing problem in Soil Physics. One of the main problems is the understanding of flow in a constantly changing transforming porous media, where the soil pores and water pathways evolve spatially and temporally, for example due to interaction with the flow, aggregates, compaction, destruction of permeability...etc. To overcome this problem, new equations are presumed to predict the water flow $\mathrm{Q}(\theta)$ and hydraulic conductivity $\mathrm{K}(\theta)$ into capillary and non-capillary pore size classes in coarse (sandy loam) and fine (clay) textured soils. Then the total hydraulic conductivity of the studied soils is predicted as a summation of hydraulic conductivity for each pore size class. The pore size classes are explained in this work as rapidly drainable pores (RDP), slowly drainable pores (SDP), water holding pores (WHP), and fine capillary pores (FCP). They were derived upon the soil moisture retention data of the studied sandy loam and clay soils. Also, the progress in this work is how to solve the problems regarding the upper limit of the rapidly drainable pores (RDP) diameter, and the expected predominant of non-laminar (turbulent) flow at saturation condition into the large pore sizes. To solve this problem the conceptual of the critical radius that found to be $r_{c}=95 \mu \mathrm{m}$ was provided in the present study. Upon the $r_{c}$ value, the RDP range was divided into two parts; (1) ranges from the upper limit of slowly drainable pores (SDP, $14.4 \mu \mathrm{m}$ ) up to the critical limit or radius, $r_{c}(=95 \mu \mathrm{m}),(2)$ ranges from $r_{c}(=95 \mu \mathrm{m})$ up to the maximum limit of pore size at full saturation. In this respect a new model, depending on water sorptivity (S) at steady state infiltration, was suggested to determine the water flow and hydraulic conductivity into the RDP upon the range of non-laminar (turbulent) water flow, i.e. from $r_{c}=$ $95 \mu \mathrm{m}$ up to the maximum size of RDP $\left(r_{\max }\right)$. To obtain the effective water content which contribute to $\mathrm{Q}(\theta)$ and $\mathrm{K}(\theta)$ values, the immobile adsorbed water (soil moisture adsorption capacity, $W a$ ) was reducted from the water content at fine capillary pores $(\theta)_{\mathrm{FCP}}$. The values of $\mathrm{K}(\theta)$ calculated by the assumed equations were in agreement with those calculated by van Genuchten's model $\left(\mathrm{K}(\theta)_{\mathrm{G}}\right)$ for WHP only. However, the calculated values of $K(\theta)$ were within the range of the commonly measured values for the studied soils, indicating the applicability of the assumed equations for predicting the unsaturated hydraulic conductivity in both coarse and fine textured soils.

\section{Acknowledgements}

I would like to express my gratitude to William DeTar, retired Agric. Engr., USD of Agric.-ARS, US Cotton Res. Station, 17053 Shafter Avenue, Shafter, CA 93263, for correcting the English language of the manuscript. His assistance is gratefully acknowledged. I am also grateful to the anonymous reviewers for their helpful comments.

\section{References}

Ahuja, L.R. Cassel, D.K., Bruce, R.R., Bames, B.B. 1989. Evaluation of spatial distribution of hydraulic conductivity using effective porosity data. Soil Science 148:404-411.

Amer,A.M. 1993. Surface area measurements as related to water vapor adsorption in arid soils of Egypt. Proc. Int. Conf. Desert Develop.,25-30 July, Mexico City, Mexico, pp.619-627. 
Amer, A.M. 2002. Drainable and water-filled pores as related to water storage and conductivity in agricultural soils of the Nile Delta. Verh. Internat. Verein. Limnology, Vol.28, part 4, p.1912-1919 Stuttgart-Germany, 28th SIL Congress, 4-10 February, 2001, Manash Univ., Melbourne, Australia.

Amer, A.M. 2003. Soil hydrophysics. Part1. El-Dar Al-Arabia for Publish \& Distrib., Cairo, Egypt. 452pp.

Amer, A.M. 2009. Moisture adsorption capacity and surface area as deduced from vapour pressure isotherms in relation to hygroscopic water of soils. Biologia 64, 3: 516-521.

Amer, A.M., Logsdon, S.D., Davis, D. 2009. Prediction of hydraulic conductivity in un- saturated soils. Soil Science 174, 9: 508- 515.

Amer, A. M. 2011. Prediction of hydraulic conductivity and sorptivity in soils at steady state infiltration. Archives of Agronomy and Soil Science. Online http://www.tandfonline.com/loi/gags20.

Baver, L.D., Gardner, W.R. 1972. Soil physics. $4^{\text {th }}$ ed. John Wiley \& Sons, New York, 498pp.

Beven, K., Germann, P.1982. Macropores and water flow in soils. Water Resour. Res. 18: 1311-1325.

Chen, C., Wagenet, R.J. 1992. Simulation of water and chemicals in macropore soils. Part 1. Representation of the equivalent macropore influence and its effect on soil water flow. J. Hydrlogy 130: 105-126.

Dane, J.H., Topp, G.C. (Eds.). 2002. Methods of soil analysis, Part 4, Physical methods. SSSA, Madison, WI. 1692 pp.

Ghazy, A.E. 1993. Pore size distribution and moisture behavior in highly calcareous soils. Egypt. J. Soil Sci. 22: 57-67.
Hallett, P.D. 2008. A brief overview of the causes, impacts and amelioration of soil water repellency - a review. Soil \& Water Res. 3, (Sp.Issue 1): S21 S29.

Hillel, D. 1980. Fundamentals of soil physics. Academic press, New York.

Klute, A., Dirksen, C. 1986. Hydraulic conductivity and diffusivity: Laboratory methods. In Methods of soil analysis. Part 1, Agron. Monogr. 9, $2^{\text {nd }}$ Ed, A. Klute (ed.). ASA and SSSA, Madison, WI, pp.687-734.

Kostiakov, A.N. 1932. On the dynamics of coefficient of water-percolation in soils and on necessity for studying it from a dynamic point of view for purposes of amelioration. Trans. $6^{\text {th }}$ Comm. Intern. Soil Sci., Russia, Part A, pp 17-21.

Marshall, T. J. 1956. Relation between water and soil. Technical Communication No. 50, Commonwealth Bureau of Soils, Farenham Royal, Bucks, England.

Mualem, Y. 1976. A new model predicting the hydraulic conductivity of unsaturated porous media. Water Resour. Res. 12:513-522.

Mundra, M.C., Raj Pal, Siyag, R.S., Poonia, S.R. 1989. Unsaturated water transmission characteristics of soils in relation to texture, aggregate size and initial moisture content. J. Agric. Sci. Camb., 112: 199-204.

Philip, J.R. 1957. The theory of infiltration:1.The infiltration equation and its solution. Soil Science 83: 345-357.

Philip, J.R., 1969. Theory of infiltration. Adv. Hydrosci. 5: 215-290. 
Reynolds, W.D., Elrick, D.E., Young, E.G. 2002. 3.4.2.a. Single - ring and double - ring or concentric - ring infiltrometers. p. 821-826. In (J.H. Dane and G.C. Topp, Eds. Methods of soil analysis Part 4 Physical methods. SSSA, Madison. WI.

Sparks, D.L. (ed.). 1996. Methods of soil analysis, Part 3, Chemical methods. ASA, SSSA, Madison, WI.
Swartzendruber, D., Young, E.G. 1974. A comparison of physically-based infiltration equation. Trans. ASAE 12:822-828.

Van Genuchten, M. Th. 1980. A closed-form equation for predicting the hydraulic conductivity of unsaturated soils. Soil Sci. Soc. Am. J. 44: 892-898.

Zhang, R. 1997. Determination of soil sorptivity and hydraulic conductivity from the disk infiltometer Soil Sci. Soc. Am. J. 61:1024-1030. 